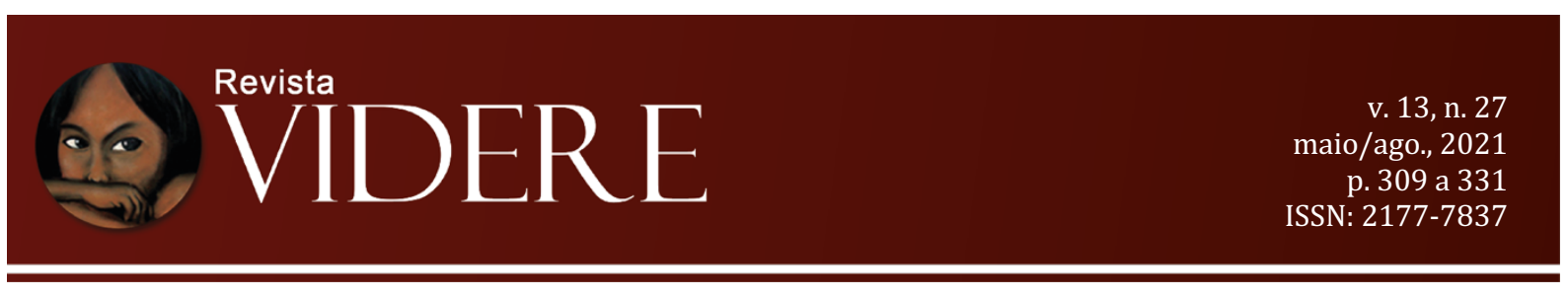

\title{
LUTAS POLÍTICAS E MOVIMENTOS DE RESISTÊNCIA NO SISTEMA AFRICANO DE DIREITOS HUMANOS: O CASO DA ORIENTAÇÃO SEXUAL
}

\author{
POLITICAL STRUGGLES AND RESISTANCE MOVEMENTS IN THE AFRICAN \\ HUMAN RIGHTS SYSTEM: THE CASE OF SEXUAL ORIENTATION
}

\section{LUCHA POLÍTICA Y MOVIMIENTOS DE RESISTENCIA EN EL SISTEMA AFRICANO DE DERECHOS HUMANOS: EL CASO DE LA ORIENTACIÓN SEXUAL}

\author{
Rui Garrido \\ Doutorando em Estudos Africanos no Instituto Universitário de Lisboa (ISCTE, Portugal) \\ Instituto Universitário de Lisboa (ISCTE, Portugal) \\ rui.a.garrido@gmail.com \\ OrcidID: https://orcid.org/0000-0002-2585-2571
}

\begin{abstract}
Resumo: O presente artigo tem como objetivo analisar o retrocesso no Sistema Africano de Direitos Humanos, na medida em que o sistema entrou em campos politicamente sensíveis como é a orientação sexual. Criada pela Carta Africana dos Direitos Humanos e dos Povos, a Comissão Africana dos Direitos Humanos e dos Povos tem o mandato de proteger, promover e interpretar os direitos e deveres consagrados na Carta Africana. No entanto, a pressão política do Conselho Executivo da União Africana ameaça minar a independência e o mandato da Comissão. Ao mapear os desenvolvimentos entre a Comissão e o Conselho Executivo no caso da Coalition of African Lesbians, este artigo analisa a evolução e a resistência do sistema africano dos direitos humanos face à pressão política hostil. Analise igualmente os argumentos evocados, nomeadamente a alegada jurisdição conflitual entre a Comissão e o Tribunal de direitos humanos. Conclui que os órgãos políticos estão a minar o sistema africano de direitos humanos em benefício das agendas políticas dos Estados.
\end{abstract}

Palavras-chave: Sistema Africano de Direitos Humanos. Coalition of African Lesbians. princípio da complementaridade. resistências.

\footnotetext{
Abstract: The present article aims to analyse the backlash in the African Human Rights System, as the system entered in political sensitive fields as it is the sexual orientation. Created by the African Charter on Human and Peoples' Rights, the African Commission on Human and Peoples' Rights is mandated to protect, promote, and interpret the rights and duties enshrined in the African Charter. Yet, political pressure by the African Union Executive Council threatens to undermine the independence and mandate of the Commission. By mapping the developments
} 
between the Commission and the Executive Council on the case of Coalition of African Lesbians, this article will shed some light about the viability of the African Human rights System facing hostile political pressure. It analyses the arguments, namely the alleged conflict of jurisdiction between the Commission and the Human Rights Court. It concludes that the political bodies are trying to undermine the whole African human rights system in benefit of State's political agendas.

Keywords: African Human Rights System. Coalition of African Lesbians. principle of complementarity. resistances.

Resumen: Este artículo tiene como objetivo analizar el retroceso en el Sistema Africano de Derechos Humanos, ya que el sistema entró en campos políticamente sensibles como la orientación sexual. Establecida por la Carta Africana de Derechos Humanos y de los Pueblos, la Comisión Africana de Derechos Humanos y de los Pueblos tiene el mandato de proteger, promover e interpretar los derechos y deberes consagrados en la Carta Africana. Sin embargo, la presión política del Consejo Ejecutivo de la Unión Africana amenaza con socavar la independencia y el mandato de la Comisión. Al mapear los desarrollos entre la Comisión y el Consejo Ejecutivo en el caso de la Coalición de Lesbianas Africanas, este artículo analiza la evolución y la resistencia del sistema africano de derechos humanos frente a la presión política hostil. Analice también los argumentos planteados, a saber, la supuesta competencia en conflicto entre la Comisión y la Corte de Derechos Humanos. Concluye que los cuerpos políticos están socavando el sistema africano de derechos humanos en beneficio de las agendas políticas de los estados.

Palabras clave: Sistema Africano de Derechos Humanos. Coalición de Lesbianas Africanas. principio de complementariedad. resistencias.

\section{Introdução}

Os líderes africanos tentaram imprimir no âmbito da Carta Africana dos Direitos Humanos e dos Povos (Carta Africana), algumas particularidades únicas que a distinguem dos sistemas europeu e interamericano de direitos humanos. Diferentemente dos sistemas regionais congéneres, no que concerne aos mecanismos de controlo, a opção africana foi por um órgão de natureza quasi jurisdicional - a Comissão Africana dos Direitos Humanos e dos Povos (Comissão). Esta Comissão teve um papel fundamental na consolidação do sistema e densificação dos direitos e dos deveres inscritos na Carta Africana.

Com a adoção do Protocolo à Carta Africana dos Direitos Humanos e dos Povos relativo ao estabelecimento do Tribunal Africano dos Direitos Humanos e dos Povos (Protocolo de Ouagadougou, ou Protocolo do Tribunal), em 1998, e consequente instalação do Tribunal Africano dos Direitos Humanos e dos Povos, em 2006, a Comissão Africana dos Direitos Humanos e dos Povos (Comissão dos Direitos Humanos) foi o único mecanismo de controlo 
do sistema africano de direitos humanos e provou ser um ator-chave no desenvolvimento e consolidação dos direitos humanos em África.

Com entrada em vigor do Protocolo de Ouagadougou, em 2004, e consequente instalação do Tribunal Africano, deu-se uma transformação significativa do sistema regional, dotando-o de um mecanismo de controlo dualista. O Tribunal Africano dos Direitos Humanos e dos Povos manteve uma ampla jurisdição sobre questões de direitos humanos, não só as consagradas na Carta Africana, mas também os direitos em "instrumentos relevantes dos Direitos Humanos ratificados pelos Estados". Embora ambos os organismos mantenham a jurisdição sobre as questões dos direitos humanos, o mandato do Tribunal dos Direitos Humanos vai muito além do mandato da Comissão.

Os recentes desenvolvimentos em matéria de orientação sexual no sistema africano dos direitos humanos tiveram forte oposição dos órgãos políticos da União Africana, em particular o Conselho Executivo, que iniciou uma campanha política agressiva contra a Comissão dos Direitos Humanos. Na cimeira da UA de junho de 2018, o Conselho Executivo da UA lançou o que se tratou de um ataque político contra a própria independência da Comissão dos Direitos Humanos. Tendo em conta estes desenvolvimentos, este artigo procura analisar o que pode ser interpretado como uma interferência do Conselho Executivo da UA no mandato e independência da Comissão. Conclui-se que o Conselho Executivo da AU procurou impedir que o Sistema Africano de Direitos Humanos evolua no seu mandato de garante da reparação por violações de direitos humanos.

Adotando uma metodologia assente no método dedutivo, este artigo assenta numa pesquisa bibliográfica em fontes documentais e bibliografia especializada. Este artigo é dividido em três secções. A primeira secção apresenta uma breve visão geral do sistema africano dos direitos humanos, da sua fundação, dos principais tratados e das instituições. A segunda secção examinará os desenvolvimentos relativos à inclusão da orientação sexual na agenda dos direitos humanos da Comissão Africana dos Direitos Humanos e dos Povos e a resposta dos órgãos políticos da União Africana face a esse desenvolvimento. A terceira secção analisa a questão de fundo da complementaridade entre os mecanismos de controlo do sistema regional africano, colocada em causa pelos órgãos políticos para influenciar a agenda dos direitos humanos em África. 


\section{$2 \mathrm{O}$ desenvolvimento do Sistema Africano de Direitos Humanos}

A descolonização do continente foi acompanhada de correntes políticas de integração regional que delinearam um projeto institucional cimentado nas relações entre nações, mas sem que tal se traduzisse num projeto de natureza mais federativo. A Organização de Unidade Africana (OUA), criada em 25 de maio de 1963, com a adoção da sua carta constitutiva, foi uma organização de integração regional de pendor mais cooperativo cooperação internacional. Ela foi o resultado de intensos debates que marcaram os primeiros anos da década de 60 do século XX e do confronto de visões muitos distintas para um projeto de integração regional. Dois grupos dominaram estes debates: o grupo de Casablanca - muito próximo de um projeto pan-africanista radical e de unidade federalista - e o grupo de Monróvia - que advogava uma visão muito mais moderada e de menor integração política (DIALLO, 2005, p. 10 - 11).

Foi precisamente a visão do grupo de Monróvia que prevaleceu na Carta da Organização de Unidade Africana, adotada em 1963. A OUA tinha como princípio basilar a "não interferência nos assuntos internos dos Estados" (ORGANIZAÇÃO DE UNIDADE AFRICANA, 1963) o qual determinou que esta fosse uma organização muito pouco interventiva em assuntos de direitos humanos ou ainda de conflito armado. Na verdade, a Carta da OUA apenas refere a palavra direitos humanos uma vez para se referir à Declaração Universal dos Direitos Humanos, da ONU, e como inspiração das relações entre Estados. Só no final da década de 70 do século XX é que há desenvolvimentos nesta matéria, apesar de os debates em torno da proteção dos direitos humanos remontarem até antes da adoção da Carta da OUA. Em 1961, um grupo de juristas africanos, sob a égide da Comissão Internacional de Juristas, reuniu-se em Lagos (Nigéria) e adotou um documento, posteriormente conhecido como a Lei de Lagos, no qual se afirmou:

Com o objetivo de dar total implementação da Declaração Universal dos Direitos Humanos, de 1948, esta Conferência convida os governos africanos a estudarem a possibilidade de se adotar uma Convenção Africana de Direitos Humanos, de tal sorte que as conclusões dessa Conferência sejam salvaguardadas pela criação de um tribunal de jurisdição apropriada, acessível a todas as pessoas sob a jurisdição dos Estados signatários (CONFERÊNCIA AFRICANA SOBRE O ESTADO DE DIREITO, 1961, tradução nossa)

Apesar desta recomendação, os líderes africanos optaram por deixar os direitos humanos fora da Carta da organização de Unidade Africana. Seria necessário passar-se mais de década e meia desde a criação da OUA para que esta se voltasse para estes assuntos. Na 
resolução 115 (XVI) de 1979, a Conferência de Chefes de Estado e de Governo da OUA decidiu, através do secretário-geral da OUA, pela criação de um comité de especialistas para redigir uma primeira versão de um tratado de direitos humanos (NALDI, 1999, 111). Este processo foi relativamente rápido. A apresentação da Carta Africana dos Direitos Humanos (doravante, Carta Africana) e dos Povos teve lugar em janeiro de 1981, em Banjul, tendo sido adotada nessa cimeira da OUA. Por este facto, a Carta Africana é comumente conhecida como Carta de Banjul.

\subsection{A Carta Africana dos Direitos Humanos e dos Povos}

A Carta Africana dos Direitos Humanos e dos Povos é a pedra angular do sistema africano de direitos humanos. Ela resultou de um momento de abertura da OUA, face demandas de uma maior proteção dos direitos humanos em África. Samson Wassara aponta que a OUA tomou a iniciativa, procurando liderar em matéria de direitos humanos, substituindo-se às ONG internacionais, que eram bastante ativas nos direitos humanos e dos povos, como é exemplo a Declaração Universal dos Direitos dos Povos (1976) de iniciativa não-governamental (WASSARA, 2001, 22).

A Carta Africana foi adotada 20 anos após a Lei de Lagos, onde se identificou a necessidade de um tratado africano de direitos humanos (DIALLO, 2005; GARRIDO, 2016; GARRIDO, 2020). A Carta Africana é um tratado inovador ao nível do direito internacional, uma vez que ela combina num único tratado vinculativo, as perspetivas culturais africanas e o direito internacional dos direitos humanos (PIRES, n.d.). Entre os aspetos mais inovadores da Carta Africana estão conceitos como os direitos coletivos - também conhecidos como direitos dos povos e que dá nome ao próprio tratado -, mas também a ausência de uma cláusula derrogativa, a igual força jurídica aos direitos civis e políticos e aos direitos económicos, sociais e culturais, ou ainda a consagração dos deveres individuais. Ou seja, a Carta Africana consagra os direitos humanos sem esquecer as raízes culturais africanas, traduzindo essa mundividência num tratado internacional de direitos humanos (MUTUA, 1995). Isto mesmo é afirmado no preâmbulo da Carta Africana que destaca "as virtudes da sua tradição histórica e dos valores da civilização africana" (ORGANIZAÇÃO DE UNIDADE AFRICANA, 1981).

Como tivemos oportunidade de referir, o conceito de direitos dos povos é um aspeto distintivo e importante da Carta e é também fulcral para as sociedades africanas. No âmbito dos direitos das pessoas ou dos direitos coletivos, encontramos o direito à autodeterminação, ao desenvolvimento e à liberdade de eliminação dos recursos naturais e ao direito à paz. $\mathrm{O}$ facto 
de a Carta Africana não fornecer uma definição do que deve ser entendido por povo foi uma estratégia dos seus relatores para evitar controvérsia e conceitos fechados (VILJOEN, 2009). Para além disso, os direitos dos povos estão alinhados, na sua base filosófica, com os deveres individuais, outra inovação importante da Carta Africana. Esta consagração triangular de direitos individuais, direitos coletivos e deveres individuais encontra a sua inspiração na matriz comunitarista das sociedades africanas. Estas perspetivas são fundamentais na conceção africana de pertença à comunidade, cujo objetivo primordial é o bem-estar coletivo em detrimento do individual (GARRIDO, 2017). Deste modo, o individuo apenas poderia almejar o acesso a determinados direitos ou privilégios se as suas relações de parentesco ou pertença a um grupo social específico lhe permitissem ascender socialmente. $\mathrm{O}$ indivíduo isolado não tem qualquer importância pois a mundivisão africana privilegia o coletivo. Do mesmo modo, a consagração de deveres individuais num tratado internacional de direitos humanos rompe com a conceção ocidental e individualista destes direitos. Além disso, a Carta Africana afirma que todos os cidadãos têm obrigações e deveres individuais não só para com outros cidadãos, mas também para com o Estado e, em última análise, para com a Comunidade Internacional.

No que se refere à ausência de uma cláusula derrogativa, existem várias opiniões diferentes sobre quais poderiam ter sido as intenções dos relatores. Alguns autores tendem a ver esta ausência como um dos pontos fortes deste tratado, uma vez tal significaria que os direitos consagrados na Carta Africana não podem ser suspensos em nenhuma circunstância (PIRES, n.d). Este é também o entendimento da Comissão Africana dos Direitos Humanos e dos Povos (BALDÉ, 2017).

Outro aspeto importante da Carta é a proteção universal dada aos direitos civis e políticos e aos direitos económicos, sociais e culturais (MOCO, 2010). Tanto os direitos civis e políticos como os direitos económicos, sociais e culturais têm, nos termos da Carta Africana, a mesma força jurídica e igual proteção (PIRES, n.d). Como resultado, este tratado abraça uma conceção holística de direitos humanos, adotando a doutrina da Declaração Universal dos Direitos do Homem (BRANT et al, 2007).

1.2. Os mecanismos de controlo do sistema africano dos direitos humanos

O sistema africano dos direitos humanos reflete aquelas que foram distintas correntes políticas que estiveram na génese do processo e, sobretudo, das resistências políticas dos Estados africanos em abdicar de parte da sua soberania nacional em favor de um projeto de unidade africana. Esta resistência traduziu-se em que o mecanismo de controlo adotado na Carta Africana tenha sido por um órgão sem força jurisdicional, que foi a Comissão Africana dos Direitos Humanos e dos Povos. 


\subsubsection{A Comissão Africana dos Direito Humanos e dos Povos}

A Comissão Africana dos Direitos Humanos e dos Povos foi criada ao abrigo do artigo 30. ${ }^{\circ}$ da Carta Africana e iniciou funções em 2 de novembro de 1987. Durante mais de uma década, a Comissão foi o único mecanismo de controlo dos direitos humanos e dos povos da Carta Africana. Este órgão está mandatado para "promover os direitos humanos e os povos e garantir a sua proteção em África" (ORGANIZAÇÃO DE UNIDADE AFRICANA 1981). Trata-se de um órgão quase judicial e as suas decisões não têm natureza vinculativa (VILJOEN, 2009). Marcolino Moco define a Comissão como um órgão técnico-jurisdicional e político, que apesar de não ser um órgão jurisdicional, tem uma importância fundamental na interpretação e codificação dos direitos e deveres da Carta Africana (MOCO, 2010). Nos termos do artigo 45. ${ }^{\circ}$ da Carta Africana, a Comissão é responsável por três grandes funções: promoção, proteção e interpretação dos direitos humanos e dos povos consagrados na Carta Africana. Para atingir estes objetivos, a Comissão realiza missões de promoção aos Estados-parte da Carta Africana, bem como implementa o mecanismo de comunicações (queixas), que fracassou nos seus objetivos (HANSUNGULE, 2009). Os Estados estão ainda obrigados à submissão de um relatório a cada dois anos, acerca das medidas de implementação dos direitos humanos, mecanismo que também tem fraquíssima adesão por parte dos Estados (HANSUNGULE, 2009).

\subsubsection{Tribunal Africano dos Direitos Humanos e dos Povos}

O sistema regional de direitos humanos distingue-se dos seus congéneres por ser um sistema que está em constante evolução, sobretudo ao nível dos seus órgãos. O final da década de 90 do século XX trouxe significativas mudanças no continente africano, desde logo pelo cessar da OUA e a criação de uma nova organização no continente (DIALLO, 2005) - a União Africana (UA) - a qual herdou todo o sistema regional direitos humanos. Em 1998, um ano antes das discussões em torno da passagem da OUA para a UA, o sistema africano de direitos humanos foi reforçado pela adoção de um protocolo para a instalação de um Tribunal de direitos humanos - o Protocolo à Carta Africana para o Estabelecimento do Tribunal Africano dos Direitos Humanos e dos Povos, ou simplesmente, Protocolo de Ouagadougou. Foi um passo significativo no reforço do sistema, uma vez que o tribunal é um órgão jurisdicional com capacidade consultiva e competência contenciosa. As decisões do Tribunal são de natureza vinculativa. O Sistema Africano distingue-se assim dos sistemas Europeu e Interamericano por 
se tratar de um sistema intermédio. Ou seja, no caso do sistema Europeu, a comissão europeia de direitos humanos foi extinta em 1998, numa altura de reestruturação do Tribunal Europeu de Direitos Humanos (TEDH). Os cidadãos dos Estados-parte da Convenção Europeia dos Direitos Humanos têm acesso direto ao TEDH. No caso Interamericano, a Comissão e a Corte Interamericanas atuam em complementaridade, cabendo à Comissão a apreciação das queixas e decisão. É à Comissão que cabe o papel de encaminhar queixas para a Corte, apenas nos casos em que a Comissão entender merecerem uma apreciação por esse órgão. No caso do sistema Africano, a ratificação da Carta Africana vincula os Estados à Comissão. Com o Tribunal foi criado por um protocolo adicional à Carta Africana, apenas os Estados que ratifiquem este documento ficam vinculados à jurisdição deste órgão. Por este facto, o Tribunal sofre de falta de eficácia e enfrenta uma resistência constante no panorama político africano. A principal fonte de resistência e recuo advém da falta de ratificação do Protocolo de Ouagadougou pelos Estados Africanos (DALY; WIEBUSCH, 2018). Dos 55 Estados que ratificaram a Carta Africana, apenas 24 Estados ratificaram o Protocolo de Ouagadougou. Dos 24 Estados que ratificaram o protocolo, apenas 7 depositaram a declaração exigida nos termos do $n^{\circ} 6$ do artigo $34^{\circ}$, que permite às $\mathrm{ONG}$ com estatuto de observador da Comissão ter acesso ao Tribunal, tendo o direito à apresentação de queixas por violações de direitos humanos (GARRIDO, 2020). A relação entre o Tribunal e a Comissão é de natureza complementar. A redação adotada pelo legislador africano aponta para a primazia da Comissão no tratamento de queixas de violação de direitos humanos, o que reforça a noção do Tribunal como mecanismo de último recurso. Alguns autores afirmam que o mandato da Comissão e do Tribunal constitui uma dupla jurisdição e que tal pode ser problemático para o sistema africano de direitos humanos. Samir Yerima argumenta que a forma como foi consagrado o princípio de complementaridade no Protocolo de Ouagadougou configura uma fragilidade normativa, que coloca a Comissão e o Tribunal com mandatos semelhantes (YERIMA, 2017). Este aspeto da dupla jurisdição será discutido mais aprofundadamente nas seguintes secções.

\section{O caminho espinhoso da orientação sexual no Sistema Africano de Direitos Humanos}

À semelhança dos demais sistemas regionais (HEINZE, 2001), bem como do sistema universal de direitos humanos, no sistema africano de direitos humanos, a orientação sexual não foi prevista como fator proibido de discriminação (GARRIDO, 2019). Nos termos do artigo $2^{\circ}$ da Carta Africana (proibição de discriminação), o legislador africano usou uma cláusula aberta nos seguintes termos: 
Cada indivíduo tem direito ao gozo dos direitos e liberdades reconhecidos e garantidos na presente Carta sem distinção de qualquer tipo, como raça, grupo étnico, cor, sexo, língua, religião, política ou qualquer outra opinião, origem nacional e social, fortuna, nascimento ou qualquer estatuto (ORGANIZAÇÃO DE UNIDADE AFRICANA, 1981, tradução nossa)

O artigo adotou uma ampla proteção, como é o caso de que "cada indivíduo" tem direito aos direitos da Carta Africana "sem distinção de qualquer tipo" por vários motivos ou "qualquer estatuto". Neste sentido, os redatores da Carta Africana optaram por uma formulação que, à semelhança dos tratados congéneres europeu e interamericanos, se pauta por uma redação ampla, universal e inclusiva (JJUUKO, 2017, 268). Por isto mesmo, e tendo em consideração que os tratados internacionais não são cristalizações de uma determinada mundivisão, mas sim instrumentos vivos que acompanham a evoluação das sociedades, uma leitura atualizada deste artigo pode acomodar a questão da orientação sexual, como foi feito, inclusive, na jurisprudência do Tribunal Europeu de Direitos Humanos - no caso Salgueiro da Silva Mouta v. Portugal (1999) - e da Corte Interamericana de Direitos Humanos - no acórdão Atalla Riffo y Niñas v. Chile (2012). No caso africano, contudo, o conhecimento da questão da orientação sexual como matéria de direitos humanos têm sido um processo muito mais complexo, o qual tem gerado avanços e retrocessos em distintas esferas da União Africana.

Apenas a Comissão tem lidado com a orientação sexual no âmbito dos direitos humanos a nível regional. Apenas em 2011, a Comissão adotou um documento relativo à interpretação dos direitos económicos, sociais e culturais da Carta Africana, no qual incluir a orientação sexual como fator proibido de discriminação. Os Princípios e Diretrizes sobre a Implementação dos Direitos Económicos, Sociais e Culturais da Carta Africana (2011) determinam que "Fatores proibidos de discriminação incluem, mas não estão limitados, (...) género, orientação sexual [ou] qualquer outra situação.” (COMISSÃO AFRICANA DOS DIREITOS HUMANOS E DOS POVOS, 2011, tradução nossa)

Por consequência, entendeu a Comissão que as pessoas de orientação sexual e identidade de género diversas encontravam-se em situação desfavorecida no acesso aos direitos elencados na Carta Africana. Determinou assim que gays, lésbicas, bissexuais, transgénero e pessoas intersexo contituiam grupos vulneráveis ou marginalizados ao abrigo da Carta Africana (Comissão Africana dos Direitos Humanos e dos Povos, 2011). Uma vez que a Comissão está mandatada para a interpretação e densificação dos direitos elencados na Carta Africana, a inclusão da orientação sexual nestas diretrizes representou, formalmente, o reconhecimento desta caraterística pessoal e individual como fator proibido de discriminação. 
As diretrizes de 2011 forem apenas o princípio de um trabalho consistente da Comissão na proteção dos direitos humanos de pessoas LGBTI. Três anos mais tarde, a Comissão adotou aquela que é a sua única resolução relativa à questão da orientação sexual; a resolução 275 - Proteção contra a Violência e outras Violações de Direitos Humanos contra pessoas com base na sua Orientação Sexual ou Identidade de Género Real ou Percecionada (2014). Nesta resolução, a Comissão insta os Estados-parte a respeitarem os direitos humanos, consagrados na Carta Africana, das pessoas LGBTI, protegendo-as da violência perpetrada por agentes estatais ou não-estatais (COMISSÃO AFRICANA DOS DIREITOS HUMANOS E DOS POVOS, 2014). Esta resolução deu esperança aos movimentos de ativismo LGBTI, que atuavam na marginalidade, face a Estados que usavam as leis coloniais contra a sodomia para perseguir as pessoas LGBTI e os coletivos.

Apesar deste lento progresso, o sistema regional africano tem falhado na sua missão de proteção dos direitos humanos das pessoas LGBTI em África. A questão da orientação sexual constitui um tema que levanta grandes sensibilidades políticas em várias sociedades africanas. O sistema tem falhado, desde logo, em dialogar com os Estados para que revoguem as leis coloniais que criminalizam os atos sexuais consentidos entre adultos do mesmo sexo. Do mesmo modo, também não tem atuado junto das lideranças políticas para que não hostilizem os seus cidadãos que têm uma orientação sexual não heterossexual. Este é, talvez, o maior desafio nesta matéria, uma vez que a retórica homofóbica dos líderes políticos africanos é frequentemente transportada para a cúpula política da União Africana e muitas vezes atua como um impedimento para abordar temas e questões LGBTI a nível regional.

\subsection{O Pântano Político da Coalition of African Lesbians}

Embora a Comissão tenha conseguido fazer alguns progressos consistentes no reconhecimento da orientação sexual e como fator proibido de discriminação ao abrigo da Carta Africana, os órgãos políticos da UA foram, em certa altura, uma fonte de grande resistência a este reconhecimento da Comissão. Em concreto, o Conselho Executivo da UA, o segundo órgão máximo, encetou uma estratégia de bloqueio da Comissão.

A Coalition of African Lesbians (CAL) é uma ONG sul-africana dedicada aos direitos das mulheres, em particular as necessidades específicas das mulheres lésbicas. Esta organização solicitou o estatuto de ONG observadora junto da Comissão Africana dos Direitos Humanos e dos Povos, em 2008. Este estatuto, ao qual aderem várias ONG africanas e internacionais, permite que as associações assistam às cimeiras da Comissão e que inclusive sugiram temas 
prementes para a Comissão apreciar. Em suma, este estatuto permite uma aproximação da Comissão às reais necessidades em matéria de direitos humanos, interagindo com quem está no terreno. No caso do pedido da CAL, este pedido foi indeferido, em 2010. Justificou a Comissão que a CAL não promovia nenhum dos direitos e dos deveres consagrados na Carta Africana. Este foi o primeiro momento de retrocesso que se assistiu no sistema africano de direitos humanos.

Contudo, ventos de mudança sopraram sobre a Comissão. Em 2011, como já referimos, este órgão adotou as diretrizes sobre os direitos económicos, sociais e culturais, incluindo a questão da orientação sexual e da vulnerabilidade das pessoas LGBTI. Este passo foi indicativo para a CAL de que uma nova tentativa deveria ser feita junto da Comissão. Um novo pedido foi efetuado em 2014 e desta vez, o desejado estatuto foi atribuído à CAL, em abril de 2015. Este estatuto traduziu-se numa vitória dos direitos humanos no continente africano.

A abertura dos órgãos de direitos humanos teve como consequência uma atitude de resistência por parte do Conselho Executivo da UA. Durante a 27 Sessão Ordinária (2015), que teve lugar em Joanesburgo, o Conselho Executivo expressou a sua reprovação em relação ao estatuto de observador concedido à Coalition of African Lesbians. Na altura, o Conselho Executivo:

SOLICITA à [Comissão] que tenha em conta os valores africanos fundamentais, a identidade e as boas tradições e que retire o estatuto de observador concedido às ONG que possam tentar impor valores contrários aos valores africanos; a este respeito, solicita à [Comissão] que reveja os seus critérios de concessão de estatuto de observador às ONG e que retire o estatuto de observador concedido à Organização CAL, em conformidade com os valores africanos (CONSELHO EXECUTIVO DA UNIÃO AFRICANA, 2015, tradução nossa)

Esta posição do Conselho Executivo, fruto da ação de alguns Estados-membros da UA, foi entendida como um sério ataque à independência da Comissão Africana dos Direitos Humanos (RAMOS, 2018, 336). O Conselho Executivo apela à Comissão a revogação de um Estatuto, com base nos alegados valores africanos, sem sequer clarificar no que consistem tais valores. É certo de que a Carta Africana se cimentar na questão dos valores da civilização africana, inclusive "existia a preocupação de uma eliminação progressiva de práticas negativas das tradições culturais africanas" (CÓ, 2018, 535), que se traduziu nos deveres individuais e, por consequência, nos próprios Estados. Neste sentido, não está apenas reservado aos cidadãos a preservação dos "valores culturais positivos, mas os Estados, principais responsáveis pela 
implementação da [Carta Africana], estivessem exonerados de preservar os valores africanos" (CÓ, 2018, 535 - 536), o que si justificou a ação do Conselho Executivo.

É certo de que a retórica política e religiosa que tem sido dominante em vários países africanos é a de que homossexualidade não é africana, constitui uma importação e atenta contra os valores da família tradicional africana (GARRIDO, 2017). No entanto, vários pesquisadores africanos, sobretudo, contestam veementemente esta visão, sustentando que a homossexualidade sempre existiu no continente, mas que a criminalização e a homofobia é que resultam da ocupação colonial (AWONDO et al, 2012; TAMALE, 2014). É preciso atender que a Carta Africana proíbe a discriminação, mas também impõe aos cidadãos o dever de respeitar os seus concidadãos na sua diferença, promovendo boas relações sociais, o que claramente não se está a verificar no caso das pessoas de orientação sexual diversa (GARRIDO, 2018). Por último e ainda a este respeito, a propósito da negação do reconhecimento da personalidade jurídica (registo) de associações LGBTI no continente africano, precisamente com base nos argumentos culturais de que tais práticas são contrárias aos valores africanos, esclarece Fernando Macedo que:

Esta justificação aduzida por vários Estados africanos como fundamento para a actuação dos poderes públicos não passa no teste da sua confrontação com o parâmetro material dos valores de uma sociedade democrática e livre, pois, salvaguardados outros direitos e bens igualmente atendíveis, o direito à autodeterminação sexual deve prevalecer e, com ele, o direito das pessoas com orientação sexual diferente a disporem da liberdade de se associarem com fins que não colidam com a "tábua de valores" da democracia liberal e de uma sociedade livre informada pelo Direito justo (MACEDO, 2018, p. 128).

Voltando à decisão do Conselho Executivo, de 2015, este solicitou uma revisão do relatório de atividades da Comissão, para atender às suas recomendações, o Centro de Direitos Humanos da Universidade de Pretória e a Coalition of African Lesbians, à época ambas ONG com o estatuto de observador junto da Comissão, solicitaram um parecer consultivo ao Tribunal Africano dos Direitos Humanos e dos Povos, indagando o Tribunal acerca da alegado interferência do Conselho Executivo no mandato da Comissão. No seu parecer, o Tribunal entendeu que apenas uma organização africana reconhecida pela União Africana tinha o direito de solicitar tais pareceres consultivos e rejeitou analisar substantivamente o caso (TRIBUNAL AFRICANO DOS DIREITOS HUMANOS, 2018). No entendimento do Tribunal, o reconhecimento de uma ONG pela Comissão Africana dos Direitos Humanos e dos Povos, não equivale a um reconhecimento da própria União Africana, uma vez que esse reconhecimento é atribuído pelo órgão político supremo, ou seja, a Conferência da União. Na nossa opinião, o 
Tribunal evitou deliberadamente apreciar a questão, furtando-se assim ao ricochete que a Comissão estava a sofrer. Consequentemente, o Tribunal abandonou a Comissão nesta luta, o que se traduziu num dos ataques mais fortes a todo o sistema africano de direitos humanos nos mais de 30 anos de existência.

Em janeiro de 2018, o Conselho Executivo insistiu que a Comissão retirasse o estatuto de observador da Coalition of African Lesbians, adotando nova decisão sobre o assunto e na qual manifesta preocupação pela recusa da Comissão implementar a decisão 887, de 2015 (CONSELHO EXECUTIVO DA UNIÃO AFRICANA, 2018). A Comissão recusou-se a retirar o estatuto de observador da CAL, afirmando no seu $43 .^{\circ}$ relatório de atividades que a Coalition of African Lesbians cumpria todos os critérios necessários para ser elegível para o estatuto de observador. A Comissão tentou igualmente reforçar o seu papel de órgão de defesa dos direitos humanos, mandatado para proteger os direitos humanos e populares consagrados na Carta Africana, afirmando que:

\begin{abstract}
A Comissão está mandatada para implementar a Carta Africana, ao abrigo da qual todos têm direito aos direitos e estão sujeitos aos deveres previstos na Carta, e é dever da Comissão proteger esses direitos em conformidade com o mandato que lhe é conferido nos termos do artigo $45 .^{\circ}$ da Carta, sem qualquer discriminação devido ao estatuto ou a outras circunstâncias (COMISSÃO AFRICANA DOS DIREITOS HUMANOS E DOS POVOS, 2017, tradução nossa)
\end{abstract}

Como resultado do relatório da Comissão, o Conselho Executivo aprovou uma nova decisão, em junho de 2018, durante a $31^{\text {a }}$ Cimeira da União Africana, num ato de grande hostilidade e atacando diretamente o mandato e a independência da Comissão. Na Decisão 1015, o Conselho Executivo estabelece que a Comissão tem até ao final do ano de 2018 para dar cumprimento à decisão 887 e revogar o estatuto da CAL (CONSELHO EXECUTIVO DA UNIÃO AFRICANA, 2018b). A Comissão de direitos humanos foi forçada a retirar o estatuto à $\mathrm{CAL}$, resultando numa vitória para o Conselho Executivo, mas uma perda para o sistema de proteção de direitos humanos no continente.

\title{
3 A existência de uma Comissão e de um Tribunal constitui uma ameaça para o Sistema Africano dos Direitos Humanos?
}

Como verificamos, o caso da CAL é ilustrativo das lutas políticas no âmbito do sistema africano de direitos humanos. O Conselho Executivo da UA, o segundo órgão político da UA e com elevado grau de influência no processo de tomada de decisão, opôs-se ferozmente às 
interpretações progressivas da Comissão em matéria de direitos humanos e orientação sexual (AMAO, 2019). A Conferência de Chefes de Estado e de Governo da UA, órgão político supremo, tem naturalmente uma forte influência sobre outros órgãos da União, incluindo o Conselho Executivo (MOCO, 2010).

\subsection{O ataque à independência da Comissão Africana dos Direitos Humanos e dos Povos}

A decisão 1015 adotada pelo Conselho Executivo, acerca da Comissão Africana, expõe uma fragilidade muito evidente do sistema africano de direitos humanos e que é a sua dependência dos Estados-membros da UA e das políticas seguidas pela União. O facto de tal reação ter sido despoletado por causa de um tema politicamente fraturante no seio da UA - a questão da homossexualidade - não nos deve fazer cair no erro de balizar esta reação apenas a temas sensíveis, mas sim despertar as consciências para a importância das lutas de direitos humanos, sejam elas quais forem.

$\mathrm{Na}$ decisão 1015, o Conselho Executivo exorta a Comissão a revogar o estatuto atribuído à CAL. Mas apenas o faz depois de frisar que a Comissão não é um órgão autónomo, dentro da arquitetura institucional da União Africana. Assim, o Conselho:

SUBLINHA QUE a independência de que a [Comissão] goza é de natureza funcional e não de independência dos mesmos órgãos que criaram o corpo, ao mesmo tempo que expressa cautela sobre a tendência da [Comissão] agir como um órgão de recurso, minando assim os sistemas jurídicos nacionais (CONSELHO EXECUTIVO DA UNIÃO AFRICANA, 2018b, tradução nossa)

Atendendo que o Conselho Executivo é o segundo órgão máximo da União Africana, esta declaração de que a Comissão apenas goza de independência funcional e não de independência política subjuga a Comissão às orientações dos órgãos políticos, que lhe são hierarquicamente superiores. Esta decisão representou um ataque sem precedentes à independência da Comissão (RAMOS, 2018) e levanta várias questões acerca do papel e da legitimidade da Comissão no âmbito do sistema africano dos direitos humanos. Por exemplo, o Conselho, nas suas decisões, decidiu levantar a questão da jurisdição da Comissão em relação ao Tribunal dos Direitos Humanos, alegando tratar-se de uma dupla jurisdição que entende ameaçar toda a integridade do sistema regional.

As decisões do Conselho Executivo da UA impõem à Comissão a obrigação de cumprir com as mesmas. Ora, estas decisão foram adotadas por um órgão estritamente político da UA, com a sua própria agenda, e cujo resultado prático foi a fragilização da própria Comissão 
de direitos humanos. Além disso, o Conselho Executivo sublinhou ainda que a independência de que a Comissão goza é de "natureza funcional" e não dos órgãos políticos da UA e afirma a sua "preocupação", relativamente à "tendência da [Comissão] que atua como órgão de recurso" que, na opinião do Conselho Executivo, prejudica os sistemas jurídicos nacionais (CONSELHO EXECUTIVO DA UNIÃO AFRICANA, 2018b).

O Conselho solicitou igualmente que os Estados Partes "procedem a uma revisão do mandato interpretativo da Comissão Africana dos Direitos Humanos e dos Povos, à luz de um mandato semelhante exercido pelo Tribunal Africano e do potencial de jurisprudência conflituosa". (CONSELHO EXECUTIVO DA UNIÃO AFRICANA, 2018b)

Embora a Comissão Africana dos Direitos Humanos e dos Povos tenha sido o único mecanismo de controlo durante mais de uma década, a sua independência foi sempre uma questão sensível (AMAO, 2019). Como já referimos anteriormente, o mandato de proteção da Comissão é complementado pelo Tribunal Africano dos Direitos Humanos e dos Povos. No que se traduz então esta complementaridade entre a Comissão e o Tribunal? É necessário, antes de mais, entender o propósito do princípio da complementaridade no direito internacional. Neste sentido, Solomon Ebobrah sustenta que:

No domínio anárquico do direito internacional, onde as instituições são criadas como entidades autónomas sem qualquer estrutura hierárquica para regular as suas interações, a complementaridade é certamente um instrumento importante para a restrição do abuso de autonomia por qualquer instituição (EBOBRAH, 2011, tradução nossa)

Entende-se, assim, que a complementaridade, num sentido mais amplo, procura limitar os excessos e a concentração de poder das instituições ao nível das esferas nacional e internacional. Ao nível internacional, são vários os casos de complementaridade entre instituições. Neste sentido, o caso internacional mais conhecido da aplicação deste princípio remete-nos para o Estatuto de Roma para o Tribunal Penal Internacional (TPI), de 1998. Neste estatuto, o seu preâmbulo prevê que o TPI "será complementar das jurisdições penais internacionais", sendo logo depois reafirmada no artigo 1. ${ }^{\circ}$ (ESTATUTO DE ROMA PARA O TRIBUNAL PENAL INTERNACIONAL, 1998). Neste caso, a complementaridade traduz-se, sobretudo, na intervenção do TPI nos casos em que os Estados não tenham condições para julgar os crimes.

Ao nível do sistema africano, a complementaridade foi primeiramente afirmada no preâmbulo do Protocolo de Ouagadougou que estabelece o Tribunal (EBOBRAH, 2011). O legislador africano procurou que o Tribunal Africano fosse um tribunal de último recurso, 
mantendo a Comissão como órgão com a competência para a apreciação de queixas de violações de direitos humanos (GARRIDO, 2020). Por outro lado, a Comissão pode encaminhar queixas para o Tribunal ao abrigo da complementaridade (RUDMAN, 2014). Esta possibilidade, na nossa opinião, torna o sistema mais robusto. No entanto, o risco de dupla jurisdição é real (YERIMA, 2017), mas o legislador também acautelou a minimização deste risco. No preâmbulo do Protocolo de Ouagadougou, pode ler-se:

Firmemente convencidos de que para se alcançarem os objetivos da Carta Africana dos Direitos do Homem e dos Povos, é necessária a criação de um Tribunal Africano dos Direitos do Homem e dos Povos, para complementar e reforçar a missão da Comissão Africana dos Direitos do Homem e dos Povos (ORGANIZAÇÃO DE UNIDADE AFRICANA, 1998)

O artigo $2 .^{\circ}$ do Protocolo define a relação entre o Tribunal e a Comissão, nos seguintes termos:

O Tribunal, tendo presente as disposições do presente Protocolo, complementa as funções de proteção que a Carta Africana dos Direitos do Homem e dos Povos [...] confere à Comissão Africana dos Direitos Humanos e dos Povos [...] (ORGANIZAÇÃO DE UNIDADE AFRICANA, 1998)

Por último, o artigo $4 .^{\circ}$, relativo aos pareceres consultivos, determina que o Tribunal pode emitir pareceres consultivos solicitados por um Estado-membro da OUA, pela OUA, qualquer um dos seus órgãos ou por qualquer organização reconhecida pela OUA, desde que "essa questão não seja relacionada com um assunto sendo examinado pela Comissão" (ORGANIZAÇÃO DE UNIDADE AFRICANA, 1998). Parece-nos bastante evidente que o legislador africano procurou reforçar o papel da Comissão, garantido que não existia situações de conflito de jurisdição entre a Comissão e o Tribunal. Apesar deste cuidado do legislador, Ebobrah aponta que a implementação de uma complementaridade sem fricções entre a Comissão e o Tribunal deve assentar numa estratégia de repartição de funções, cabendo ao Tribunal todos os atos adjudicatórios, enquanto que a Comissão deveria estar focada nas resoluções amigáveis e nas missões de fact-fiding e outras investigações (EBOBRAH, 2011).

\subsection{O impacto da decisão 1015 nos cidadãos}

Convém recordar, como já afirmamos anteriormente, que cidadãos têm o direito de queixa junto da Comissão por violações dos direitos humanos, o que não acontece com o Tribunal. Para este, os Estados têm de ratificar o Protocolo de Ouagadougou. Esta situação 
configura, à priori, uma discriminação dentro do sistema africano, pois apenas alguns Estados podem prestar contas no Tribunal, enquanto que outros cometem violações dos direitos da Carta Africana e não são responsabilizados por esses atos.

Ora, se a Comissão ficar limitada na receção destas queixas, ou num cenário hipotético muito mais extremo, este órgão fosse extinto, ficando apenas o Tribunal como órgão de defesa dos direitos humanos, tal representaria um retrocesso significativo de várias décadas na promoção e proteção dos direitos humanos em África. Nesta situação mais extrema - a extinção da Comissão, o que aproximaria o sistema africano daquela experiência europeia - apenas fará sentido no caso de os órgãos políticos da UA tornarem o Protocolo de Ouagadougou de aplicação obrigatória para todos os Estados signatários da Carta Africana. Por outro lado, o cenário de uma Comissão de Direitos Humanos politicamente mais limitada no seu mandato implica, na nossa opinião, que a Comissão e o Tribunal se articulem de forma mais eficiente no exercício do princípio da complementaridade. Esta articulação torna-se absolutamente central uma vez que os cidadãos não têm acesso direto ao Tribunal.

Como o Protocolo de Ouagadougou é de natureza facultativa, e mesmo no caso de ratificação deste protocolo o Estado tem ainda o poder de decidir se aceita que os seus cidadãos acedam diretamente ao Tribunal, percebemos que os Estados detêm muito controlo sobre este processo. E na verdade, a maioria dos Estados africanos não ratificou o Protocolo de Ouagadougou, e para aqueles que o fizeram, poucos depositaram a declaração que permite o acesso dos seus cidadãos ao Tribunal. Este cenário de esvaziamento da Comissão, ou a sua extinção, acabaria por servir os interesses dos Estados africanos, uma vez que os seus cidadãos não seriam capazes de responsabilizar o Estado perante o Tribunal por violações dos direitos humanos (BIEGON, 2018).

Tendo este cenário em consideração, a limitação da autonomia e da independência da Comissão só pode ser entendida como uma tentativa de minar todo o sistema africano de direitos humanos e impedir quaisquer alterações ou interpretações significativas da Carta que possam favorecer uma agenda mais progressista em termos de direitos humanos. Por outras palavras, esta limitação serve uma agenda pouco democrática dos Estados africanos, que não se querem submeter ao escrutínio internacional por violações de direitos humanos.

A limitação da autonomia e da independência da Comissão deve ser lida com o atual esvaziamento do Tribunal Africano, na qual os Estados estão a remover a declaração que permite o acesso dos cidadãos (GARRIDO, 2020). Esta conjuntura aproxima o sistema africano do sistema interamericano de direitos humanos, com a diferença significativa do Tribunal não 
estar previsto no tratado fundador do sistema - respetivamente, a Carta Africana e o Pacto de São José - o que acentua as desigualdades no acesso à justiça dos cidadãos africanos.

É nossa convicção de que a posição do Conselho Executivo representa uma subversão do mandato de proteção da Comissão, mas também de todo o sistema regional de direitos humanos, que não devia ter sido tolerado pela Conferência de Chefes de Estado e de Governo da União Africana. Em particular, esta decisão de limitação da autonomia e da independência da Comissão, a fim de manter o statu quo em matéria de direitos humanos em África, tem o potencial de minar e bloquear qualquer avanço nos direitos humanos e não apenas relativo à questão da orientação sexual.

A decisão do Conselho Executivo visa não só impedir a Comissão de cumprir o seu mandato em matéria de direitos humanos, como está efetivamente a impedir a Comissão de adotar decisões ou interpretações que possam implicações políticas que reflitam sobre os Estados e sobre os quais estes têm a maior resistência. No entanto, ao fazer tal ataque hostil, os órgãos políticos da UA minaram o mandato da Comissão, mas também do Tribunal, bem como a confiança dos cidadãos em relação aos direitos humanos, ao Estado de Direito e às instituições da União Africana. A complementaridade dos dois organismos em matéria de direitos humanos assegura que ambos os órgãos trabalhem em cooperação para criar melhores padrões de proteção dos direitos humanos, estando a Comissão na vanguarda dessa interpretação. Embora reconheçamos que a dupla jurisdição no sistema africano dos direitos humanos está longe de ser o cenário ideal, argumentamos que não só não é uma ameaça ao sistema africano dos direitos humanos, como também que o mandato e a independência da Comissão devem ser reforçados.

\section{Conclusão}

A Comissão Africana dos Direitos Humanos e dos Povos é de importância central para o sistema africano dos direitos humanos. O sistema é ainda muito recente em comparação com os sistemas europeu e interamericano, mas é aquele em que se tem verificado transformações mais profundas e fricções políticas. Este processo conturbado de consolidação é necessário, uma vez que o sistema continua fraturado por numerosas questões políticas, como no caso dos direitos humanos e da orientação sexual. Cumprindo o seu mandato de proteção, a Comissão Africana dos Direitos Humanos e dos Povos manifestou preocupação com as violações dos direitos humanos das pessoas LGBTI em África e concedeu estatuto de observador a ONG que trabalham diretamente em questões de direitos humanos e orientação sexual, como a CAL. Em consequência destes desenvolvimentos, o Conselho Executivo da União Africana expressou a 
sua discordância e adotou medidas hostis que representam uma interferência direta na independência e na autonomia da Comissão. Além disso, um dos órgãos mais importantes da União Africana, a Conferência de Chefes de Estado e de Governo da UA manteve-se em silêncio sobre o assunto. Este silêncio constitui uma anuência e alinhamento com a posição adotada pelo Conselho Executivo, furtando-se das suas responsabilidades. Esta interferência de um órgão político no mandato e independência de um órgão de direitos humanos suscita sérias preocupações quanto à dimensão da pressão política que é exercida sobre os sistemas de direitos humanos. A decisão 1015 do Conselho Executivo da UA é uma interferência inaceitável no mandato e no papel de proteção da Comissão. Os direitos humanos são universais, indivisíveis e inalienáveis, que também se aplica à orientação sexual. Esta questão individual foi suficiente para desencadear uma intensa luta política interna entre as instituições da União Africana. Os sistemas europeu e interamericano de direitos humanos já abordaram questões relacionadas com a orientação sexual, permitindo que todo o sistema evoluísse e expandisse o seu mandato de proteção. Também nestes casos se verificou forte resistência, mas as instituições mantiveram-se resilientes na sua missão de proteção dos direitos humanos. O que distingue o sistema africano é a constante e agressiva ingerência dos órgãos políticos da UA e o enfraquecimento das instituições de direitos humanos. Esta interferência dificulta o desenvolvimento do sistema regional de direitos humanos. Após 70 anos desde a adoção da Declaração Universal dos Direitos do Homem e como demonstra o caso da Coalition of African Lesbians, continuam a existir inúmeros desafios que impedem o sistema africano de direitos humanos de evoluir um padrão adequado de proteção para todos os cidadãos africanos.

Por outro lado, a estratégia do Conselho Executivo pautou-se pelo questionamento da duplicação da jurisdição entre a Comissão e o Tribunal de Direitos Humanos. O princípio da complementaridade foi previsto no Protocolo do Tribunal de forma a minimizar este risco de conflito de jurisdição. Reconhecendo, no Protocolo de Ouagadougou, que a Comissão é o órgão com primazia na apreciação de queixas de violações de direitos humanos - ainda que se trate de um órgão quasi jurisdicional -, na nossa opinião, o legislador africano reduziu o risco de conflitualidade entre a Comissão e o Tribunal. A Comissão pode encaminhar casos para o Tribunal, desde que este tenha jurisdição sobre o respetivo Estado, e o Tribunal não pode apreciar um caso se este estiver a ser analisado pela Comissão. Esta relação complementar robustece todo o mecanismo de supervisão do sistema africano. Por isto mesmo, a decisão 1015 do Conselho Executivo apenas pode ser lida como uma interferência deliberada, com o intuito de controlar o impacto que o sistema de direitos humanos possa ter nos Estados. A constrição do espaço político deve fazer que a Comissão e o Tribunal estreitem relações e se articulem de 
forma mais eficiente, respeitando o princípio da complementaridade, mas sobretudo, respeitando as expectativas e a confiança que os cidadãos têm nestas instituições.

\section{Referências}

AMAO, Femi. African Union Law: the emergence of a sui generis legal order. London: Routledge, 2019.

AWONDO, Patrick et al. Homophobic African? Toward A More Nuanced View. In: African Studies Review, vol 55, n. ${ }^{\circ} 3,2012$, p. $145-168$. Disponível online em: http://doi.org/10.1017/S0002020600007241. Acedido em: 27 de setembro de 2018.

\section{BALDÉ, Aua. O Sistema Africano de Direitos Humanos e a experiência dos Países} Africanos de Língua Oficial Portuguesa. Lisbon: Universidade Católica Editora, 2017.

BIEGON, Japhet. The Rise and Rise of Political backlash: African Union Executive Council's decision to review the mandate and working methods of the African Commission. Blog of the European Journal of International Law, 2 de agosto de 2018. Disponível em: https://www.ejiltalk.org/the-rise-and-rise-of-political-backlash-african-union-executivecouncils-decision-to-review-the-mandate-and-working-methods-of-the-african-commission/. Acedido em 26 de setembro de 2018.

BRANT, Leonardo Nemer Caldeira et al. O Sistema Africano de Proteção dos Direitos Humanos e dos Povos. 2007. Disponível em:

http://www.dhnet.org.br/direitos/sip/africa/ua_brant_sistema_africano_leonardo_nemer_calde ira_brant.pdf. Acesso em: 20 de março de 2019.

CÓ, Pedro Rosa. Artigo 66. ${ }^{\circ}$ In: JERÓNIMO, Patrícia et al. (eds.). Comentário Lusófono à Carta Africana dos Direitos Humanos e dos Povos. Braga: Observatório Lusófono dos Direitos Humanos, 2018, p. 533 - 560. Disponível online em:

https://oldhum.weebly.com/uploads/4/4/2/6/4426122/comentário_lusófono_à_carta_africana_ dos_direitos_humanos_e_dos_povos.pdf. Acedido em 10 de janeiro de 2019 .

COMISSÃO AFRICANA DOS DIREITOS HUMANOS E DOS POVOS. 43. ${ }^{\mathbf{0}}$ Relatório de atividades da Comissão Africana dos Direitos Humanos e dos Povos. 2017. Disponível em: http://www.achpr.org/files/activity-reports/43/43rd_activity_report_eng.pdf. Acedido em 2 de maio de 2019.

COMISSÃO AFRICANA DOS DIREITOS HUMANOS E DOS POVOS. 275 Resolution on Protection against Violence and other Human Rights Violations against Persons on the basis of their real or imputed Sexual Orientation or Gender Identity. 2014. Disponível em: https://www.achpr.org/sessions/resolutions?id=322. Acedido em 6 de maio de 2019.

COMISSÃO AFRICANA DOS DIREITOS HUMANOS E DOS POVOS. Principles and Guidelines on the Implementation of Economic, Social and Cultural rights in the African Charter on Human and Peoples' Rights. 2011. Disponível em: https://www.achpr.org/public/Document/file/English/achpr_instr_guide_draft_esc_rights_eng .pdf. Acedido em 6 de maio de 2019. 
CONFERÊNCIA AFRICANA SOBRE O ESTADO DE DIREITO, Lagos, Nigeria, 1961. A Report on the proceeding of the conference. Genebra: Comissão Internacional de Juristas, 1961.

CONSELHO EXECUTIVO DA UNIÃO AFRICANA. Decison on the Report on the joint retreat of the permanent representatives' committee (PRC) and the African Commission on Human and Peoples' Rights (ACHPR) EX.CL/Dec.1015(XXXIII). União Africana, https://au.int/sites/default/files/decisions/34655-ex_cl_dec_1008_-1030_xxxiii_e.pdf. Acedido em 24 de abril de 2019.

CONSELHO EXECUTIVO DA UNIÃO AFRICANA. Decision on African Commission on Human and Peoples' Rights EX.CL/Dec.995(XXXII). União Africana, 2018. Disponível online em: https://au.int/sites/default/files/decisions/33909-ex_cl_decisions_986-1007_e.pdf. Acedido em 24 de abril de 2019.

CONSELHO EXECUTIVO DA UNIÃO AFRICANA. Decision on the Thirty-eighth activity report of the African Commission on Human and Peoples' Rights EX.CL/Dec.887(XXVII). Joanesburgo: União Africana, 2015. Disponível online em: https://au.int/sites/default/files/decisions/31762-ex_cl_dec_873_-_898_xxvii_e.pdf. Acedido em 23 de abril de 2019.

DALY, Tom, WIEBUSCH, Micha. The African Court on Human and Peoples' Rights: mapping resistance against a young court. In: International Journal of Law in Context, Cambridge, volume 14, 2018, p. 294 - 313. DOI: 10.1017/S1744552318000083.

DIALLO, Alfa O. Integração Africana: da Organização de Unidade Africana à União Africana. Espaço Jurídico Journal of Law, v. 6, n. 1, p. 7-20, 9, 2015.

EBOBRAH, Solomon. Towards a Positive Application of Complementarity in the African Human Rights System: Issues of Functions and Relations. In: European Journal of International Law, Vol. 22, n. ${ }^{\circ}$ 3, 2011, p. 663 - 688. Disponível online em: https://doi.org/10.1093/ejil/chr049. Acedido em 22 de janeiro de 2019.

\section{ESTATUTO DE ROMA PARA O TRIBUNAL PENAL INTERNACIONAL, 1998.}

GARRIDO, Rui. Reflections about the African Court on Human and Peoples' Rights twenty years after the Ouagadougou Protocol. In: GRILLI, Matteo; GERITS, Frank (eds.). Visions of African Unity: New Perspectives on the History of Pan-Africanism and African Unification Projects. Cham: Palgrave MacMillan, 2020, p. 317 - 343.

GARRIDO, Rui. Patterns of discrimination based on sexual orientation in Africa: is there a Lusophone exception?. In: African Human Rights Yearbook, vol. 3, 2019, p. 93 - 118. Disponível online em: https://www.ahry.up.ac.za/garrido-r\#a4. Acedido em 14 junho de 2020.

GARRIDO, Rui. Artigo 28. . In: JERÓNIMO, Patrícia et al. (eds.). Comentário Lusófono à Carta Africana dos Direitos Humanos e dos Povos. Braga: Observatório Lusófono dos Direitos Humanos, 2018, p. 309 - 314. Disponível online em:

https://oldhum.weebly.com/uploads/4/4/2/6/4426122/comentário_lusófono_à_carta_africana_ dos_direitos_humanos_e_dos_povos.pdf. Acedido em 10 de janeiro de 2019. 
GARRIDO, Rui. Direitos Humanos das minorias LGBTI em África: uma proposta de análise entre o Universalismo e o Relativismo Cultural. In: SCIENTIA IVRIDICA, Braga, Tomo 345,2017 , p. $381-402$.

GARRIDO, Rui. O Sistema Africano dos Direitos Humanos em Transformação? A criação do Tribunal Africano de Justiça e Direitos Humanos e os desafios à proteção dos direitos humanos em África. In JERÓNIMO, Patrícia (org.). Temas de Investigação em Direitos Humanos para o Século XXI. Braga: Escola de Direito da Universidade do Minho, Direitos Humanos - Centro de Investigação Interdisciplinar, 2016, p. 331 - 344.

HANSUNGULE, Michelo. African Courts and the African Commission on Human and Peoples' Rights. In BÖSL, Anton; DIESCHO, Joseph (eds.). Human Rights in Africa: Legal Perspectives on their protection and promotion. Windhoek: Macmillan Education Namibia, 2009 , p. $233-271$.

HEINZE, Eric. Sexual Orientation and International Law: A study in the manufacture of cross-cultural "sensitivity". In: Michigan Journal of International Law, vol. 22, n. ${ }^{\text {o }}$ 2, 2001, p. 283 - 309. Disponível online em: http://repository.law.umich.edu/mjil/vol22/iss2/2. Acedido em 20 agosto de 2020.

JJUUKO, Adrian. The Protection and promotion of LGBTI Rights in the African Regional Human Rights System: Opportunities and Challenges. In: NAMWASE, Sylvie; JJUUKO, Adrian (eds.). Protecting the human rights of Sexual Minorities in contemporary Africa. Pretória, Pretoria University Law Press, 2017, p. 260 - 300.

MACEDO, Fernando. Artigo 10. . In: JERÓNIMO, Patrícia et al. (eds.). Comentário Lusófono à Carta Africana dos Direitos Humanos e dos Povos. Braga: Observatório Lusófono dos Direitos Humanos, 2018, p. 121 - 130. Disponível online em:

https://oldhum.weebly.com/uploads/4/4/2/6/4426122/comentário_lusófono_à_carta_africana_ dos_direitos_humanos_e_dos_povos.pdf. Acedido em 10 de janeiro de 2019.

MOCO, Marcelino. Direitos Humanos e seus Mecanismos de Protecção. As particularidades do Sistema Africano. Coimbra: Almedina, 2010.

MUTUA, Makau. The Banjul Charter and the African Cultural Fingerprint: An Ecaluation of the Language of Duties. In: Virginia Journal of International Law, vol. 35, 1995, p. 339 380. Disponível online em:

https://digitalcommons.law.buffalo.edu/cgi/viewcontent.cgi?article=1578\&context=journal_a rticles. Acedido em 16 de janeiro de 2019.

PIRES, Maria. Carta Africana dos Direitos Humanos e dos Povos". Gabinete de Documentação e Direitos Comparado. Disponível em: http://www.gddc.pt/actividadeeditorial/pdfs-publicacoes/7980-b.pdf. Acedido em 12 de março 2019.

ORGANIZAÇÃO DE UNIDADE AFRICANA. Protocolo à Carta Africana dos Direitos Humanos e dos Povos relativo ao estabelecimento do Tribunal Africano dos Direitos Humanos e dos Povos. 1998. 
ORGANIZAÇÃO DE UNIDADE AFRICANA. Carta Africana dos Direitos Humanos e dos Povos. 1981.

ORGANIZAÇÃO DE UNIDADE AFRICANA. Carta da Organização de Unidade Africana. 1963.

RAMOS, Benfeito Mosso. Artigo 42. ․ In: JERÓNIMO, Patrícia et al. (eds.). Comentário Lusófono à Carta Africana dos Direitos Humanos e dos Povos. Braga: Observatório Lusófono dos Direitos Humanos, 2018, p. 363 - 366. Disponível online em:

https://oldhum.weebly.com/uploads/4/4/2/6/4426122/comentário_lusófono_à_carta_africana_ dos_direitos_humanos_e_dos_povos.pdf. Acedido em 10 de janeiro de 2019.

RUDMAN, Annika. The Commission as a Party before the Court - Reflections on the Complementary Arrangement. In: Potchefstroom Electronic Law Journal, vol. 19, n. ${ }^{o}$, 2016, p. 1 - 29. Disponível online em: https://doi.org/10.17159/1727-3781/2016/v19i0a1225. Acedido em 23 de janeiro de 2019.

TAMALE, Sylvia. Homosexuality in not un-African. 26 de abril de 2014, Aljazeera. Disponível em :

http://america.aljazeera.com/opinions/2014/4/homosexualityafricamuseveniugandanigeriaethi opia.html. Acedido em 3 de outubro de 2018.

TRIBUNAL AFRICANO DOS DIREITOS HUMANOS E DOS POVOS. Centro de Direitos Humanos da Universidade de Pretória e a Coalition of African Lesbians Opinião Consultiva 002/2015. 2018. Disponível online em: https://www.africancourt.org/cpmt/advisory-finalised. Acedido em 16 dezembro de 2018.

VILJOEN, Frans. Centre for Human Rights calls for autonomy and independence of the African Commission to be reaffirmed; and for action on Cameroon and Eritrea. 28 de abril de 2018. Disponível em :

http:/www.chr.up.ac.za/images/centrenews/2018/files/2018_centre_calls_for_autonomy_and _independence_of_african_commission_to_be_reaffirmed_and_for_action_on_cameroon_an $\overline{\mathrm{d}}$ _eritrea.pdf. Ace $\overline{d i d o}$ em $\overline{2}$ de abril de $\overline{2} 01 \overline{9}$.

VILJOEN, Frans The African Regional Human Rights System. In: Krause, C. and M. Scheinin, (eds.). International Protection of Human Rights: A Textbook. Turku: Abo Akademi University Institute for Human Rights.

YERIMA, Samir. La Cour et la Commission africaines des droits de l'homme et des peuples: noces constructives ou cohabitation ombrageuse?. African Human Rights Yearbook, volume 1, 2017, p. 357 - 385. Disponível online em

http://www.pulp.up.ac.za/images/pulp/books/journals/AHRY/Yerima.pdf. Acedido em 16 de abril de 2018.

WASSARA, Samson Samuel. The African Charter on Human and Peoples Rights: A Critical Analysis. In: University of Juba Journal of Arts and Sciencies, 2001, p. 16-28.

Data de recebimento: 03.02.2021

Data de aprovação: 20.07.2021 